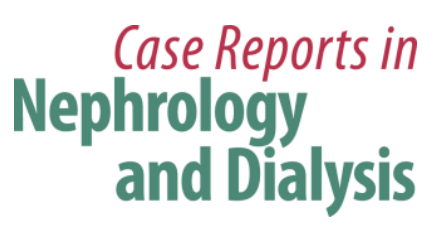

\title{
Two Types of Renovascular Lesions in Lupus Nephritis with Clinical Thrombotic Thrombocytopenic Purpura
}

\author{
Akinari Sekine $^{a} \quad$ Eiko Hasegawa $^{a}$ Rikako Hiramatsu $^{\mathrm{a}}$ Koki Mise $^{\mathrm{a}}$ \\ Keiichi Sumida ${ }^{a}$ Toshiharu Ueno $^{a}$ Masayuki Yamanouchi ${ }^{a}$ \\ Noriko Hayami $^{a} \quad$ Tatsuya Suwabe $^{a} \quad$ Junichi Hoshino ${ }^{a}$ Naoki Sawa ${ }^{a}$ \\ Kenmei Takaichi ${ }^{\mathrm{a}} \mathrm{c}$ Kenichi Ohashi ${ }^{\mathrm{b}}$ Takeshi Fujii $^{\mathrm{b}}$ Yoshifumi Ubara $^{\mathrm{a}}{ }^{\mathrm{c}}$ \\ ${ }^{a}$ Nephrology Center, ${ }^{b}$ Department of Pathology, and ${ }^{\mathrm{C} O k i n a k a}$ Memorial Institute for \\ Medical Research, Toranomon Hospital, Tokyo, Japan
}

\section{Key Words}

Lupus nephritis - Vascular lesions - Lupus vasculopathy - Thrombotic microangiopathy · Thrombotic thrombocytopenic purpura

\begin{abstract}
Renovascular lesions of lupus nephritis (LN) were classified into five categories by D'Agati in Heptinstall's Pathology of the Kidney, with thrombotic microangiopathy (TMA) and clinical thrombotic thrombocytopenic purpura (TTP) being combined. We encountered 2 cases with histological LN (class III and lass V), and they presented with clinical features of TTP, such as acute renal failure, microangiopathic hemolytic anemia, thrombocytopenia, fever, and central neurologic symptoms. Immunosuppressive therapy with plasmapheresis was performed in both patients. Case 1 progressed to end-stage renal failure requiring dialysis and died, while case 2 responded to treatment. In case 1 , small renal arteries showed positive mural staining for IgG and C3, while intraluminal material was negative for IgG and C3 [although it was positive for phosphotungstic acid-hematoxylin (PTAH), indicating fibrin deposition]. In case 2, small renal arteries showed mural staining for IgG, $\mathrm{C} 1 \mathrm{q}$, and $\mathrm{C} 3$, with the intraluminal material also being positive for these immunoglobulins, but negative for PTAH. These cases suggest that immunosuppressive therapy with plasmapheresis can control LN when intravascular thrombosis is related to immune complexes associated with activation of the early complement components $\mathrm{C} 1 \mathrm{q}$ and $\mathrm{C} 3$. In contrast, immunosuppressive therapy with plasmapheresis
\end{abstract}




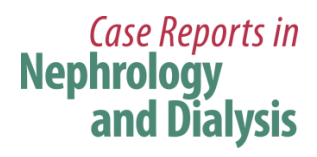

Case Rep Nephrol Dial 2015;5:192-199

DOI: $10.1159 / 000441107$

C) 2015 S. Karger AG, Basel

www.karger.com/cnd

Sekine et al.: Two Types of Renovascular Lesions in Lupus Nephritis with Clinical Thrombotic Thrombocytopenic Purpura

may not be effective when intravascular thrombosis is unrelated to these factors and involves fibrin deposition. Accordingly, in LN patients with clinical features of TTP, we report two types of renovascular lesions, in addition to typical vascular change of TMA with no immune deposits seen in nonlupus patients.

(C) 2015 S. Karger AG, Basel

\section{Introduction}

Thrombotic thrombocytopenic purpura (TTP) is a clinical syndrome that is classically characterized by five features, which are microangiopathic hemolytic anemia, thrombocytopenic purpura, fever, neurological abnormalities, and renal disease. Thrombotic microangiopathy (TMA) is a condition in which widespread thrombosis affects the microcirculation, and fibrin thrombi in the glomeruli and small arteries (including arterioles and interlobular arteries) of the kidneys can cause acute renal damage in TMA patients [1]. The differential diagnosis of TTP is extensive, including connective tissue diseases such as systemic lupus erythematosus (SLE) and systemic sclerosis. Acquired idiopathic TTP develops when high shear stress in the microcirculation promotes the formation of aggregates by von Willebrand factor (vWF) and platelets. The propensity of vWF and platelets to form microvascular thrombi is mitigated by the disintegrin and metalloproteinase with thrombospondin type 1 motif 13 (ADAMTS13), which cleaves vWF. However, the role of ADAMTS13 in SLE remains controversial $[2,3]$.

In 1994, Appel et al. [4] proposed that the renovascular complications of SLE should be classified separately with respect to histopathological changes and clinical manifestations. In 2014, D'Agati and Stokes [5] reclassified the vascular lesions of lupus nephritis (LN) into five categories in 'Heptinstall's Pathology of the Kidney'. According to both D'Agati and Appel, patients with histological evidence of TMA (fibrin thrombi in the small renal arteries and negative staining for $\operatorname{IgG}$ ) share the clinical features of hemolytic uremic syndrome (HUS)/TTP.

However, we encountered 2 patients with clinical features of TTP who showed staining of the walls of small renal arteries for immunoglobulins (including IgG and IgA) and complement component C3. Case 1 was refractory to immunosuppressive therapy and plasma exchange, progressing to end-stage renal failure that required dialysis. In this patient, intraluminal material was negative for IgG and $\mathrm{C} 3$, although it showed positive staining for phosphotungstic acid-hematoxylin (PTAH), indicating fibrin deposition. This patient may fit into the TMA category of LN. Case 2 responded to treatment, and intraluminal material showed staining for IgG, C1q, and C3, but was negative for PTAH. This patient may fit the category of noninflammatory necrotizing vasculopathy (lupus vasculopathy). We report two types of renovascular lesions in LN patients with clinical features of TTP.

\section{Case Presentations}

Case 1

A 27-year-old Japanese woman was admitted to our institution for evaluation of fever (temperature above $38^{\circ} \mathrm{C}$ ), bilateral polyarthralgia affecting the hands, feet, knees, and elbows, edema of the lower extremities, disturbance of consciousness, and renal dysfunction with a serum creatinine (Cre) of $1.4 \mathrm{mg} / \mathrm{dl}$. Seven days later, her Cre became $3.2 \mathrm{mg} / \mathrm{dl}$, urea nitrogen (UN) 52 was $\mathrm{mg} / \mathrm{dl}$, total protein (TP) was $6.5 \mathrm{~g} / \mathrm{dl}$, albumin was $2.6 \mathrm{~g} / \mathrm{dl}$, and lactate dehydrogenase $(\mathrm{LDH})$ was $676 \mathrm{IU} / \mathrm{l}($ normal: $<250)$. The white blood cell count was 


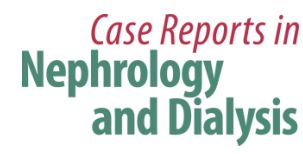

\begin{tabular}{l|l}
\hline Case Rep Nephrol Dial 2015;5:192-199 \\
\hline DOI: 10.1159/000441107 & $\begin{array}{l}\text { C 2015 S. Karger AG, Basel } \\
\text { www.karger.com/cnd }\end{array}$ \\
\hline
\end{tabular}

Sekine et al:: Two Types of Renovascular Lesions in Lupus Nephritis with Clinical Thrombotic Thrombocytopenic Purpura

$1,700 / \mu \mathrm{l}$, hemoglobin was $5.2 \mathrm{~g} / \mathrm{dl}$, and the platelet count was $5.4 / 10^{4} / \mu \mathrm{l}$. Urinary protein excretion was $3.0 \mathrm{~g}$ daily, and the sediment contained more than 30 erythrocytes per highpower field (HPF). Immunological tests revealed that anti-double-stranded DNA (dsDNA) antibody was $119.0 \mathrm{IU} / \mathrm{ml}$ (normal: <12.0) and antinuclear antibody was $25.0 \mathrm{IU} / \mathrm{ml}$ (normal: <20.0). Serum C3 was $14 \mathrm{mg} / \mathrm{dl}$ (normal: $>86 \mathrm{mg} / \mathrm{dl}$ ), C4 was $7 \mathrm{mg} / \mathrm{dl}$ (normal: $>18$ $\mathrm{mg} / \mathrm{dl}$ ), and CH50 was $2 \mathrm{U} / \mathrm{ml}$ (normal: $>30 \mathrm{U} / \mathrm{ml}$ ). Anti-cardiolipin antibody was negative, including anti-beta2 glycoprotein antibody and lupus anticoagulant. Haptoglobin was 12.1 $\mathrm{mg} / \mathrm{dl}$ (normal: $>100 \mathrm{mg} / \mathrm{dl}$ ). Prothrombin time, partial thromboplastin time, and fibrin degradation product were all normal. ADAMTS13 activity and inhibitor levels were not evaluated. LN with TTP was diagnosed from these findings. Treatment was started with prednisolone $(60 \mathrm{mg} /$ day) plus concomitant methylprednisolone pulse therapy $(500 \mathrm{mg} /$ day for 3 days). Then, plasma exchange using fresh frozen plasma (FFP) $(3,000 \mathrm{ml} /$ day $\times 3$ days $)$ was added, and hemodialysis was initiated. However, she did not respond to these treatments and lapsed into a deep coma with seizures (table 1). She died 2 months later and autopsy was performed.

\section{Case 2}

A 26-year-old Japanese woman was admitted to another institution for evaluation of fever (temperature more than $38^{\circ} \mathrm{C}$ ), malaise, and bleeding from the mouth. Cre was 1.4 $\mathrm{mg} / \mathrm{dl}$, UN was $40 \mathrm{mg} / \mathrm{dl}$, and urinary protein and occult blood were positive. Immunological tests revealed that dsDNA was $78.0 \mathrm{IU} / \mathrm{ml}$, antinuclear antibody was positive, serum C3 was $48 \mathrm{mg} / \mathrm{dl}$, C4 was $3 \mathrm{mg} / \mathrm{dl}$, and CH50 was $13 \mathrm{U} / \mathrm{ml}$. In addition, haptoglobin was $6.0 \mathrm{mg} / \mathrm{dl}$ and pancytopenia was evident. Prothrombin time and partial thromboplastin time were within normal limits, though mild elevation of fibrin degradation product was seen. She developed disturbance of consciousness with generalized tonic-clonic convulsions. LN with TTP was diagnosed. Treatment was started with prednisolone $(50 \mathrm{mg} /$ day $)$ plus methylprednisolone pulse therapy ( $500 \mathrm{mg} /$ day for 3 days, 3 times daily), cyclosporin A ( $250 \mathrm{mg} /$ day), and vincristine $(1 \mathrm{mg} /$ day). After $1 \mathrm{month}$, this patient was transferred to our institution. On admission, Cre was decreased to $0.8 \mathrm{mg} / \mathrm{dl}$, UN $15 \mathrm{mg} / \mathrm{dl}$, TP was $5.7 \mathrm{~g} / \mathrm{dl}$, albumin was $3.1 \mathrm{~g} / \mathrm{dl}$, and LDH was $685 \mathrm{IU} / \mathrm{l}$ (normal: $<250 \mathrm{IU} / \mathrm{l}$ ). The white blood cell count was $2,300 / \mu \mathrm{l}$, hemoglobin was $7.9 \mathrm{~g} / \mathrm{dl}$, and the platelet count was $6.5 / 10^{4} / \mu \mathrm{l}$. Urinary protein excretion was $3.2 \mathrm{~g} /$ day, and the sediment contained more than 30 erythrocytes per HPF. Immunological tests revealed that dsDNA was decreased to $2.8 \mathrm{IU} / \mathrm{ml}$, C3 was 62 $\mathrm{mg} / \mathrm{dl}$, C4 was $6 \mathrm{mg} / \mathrm{dl}$, and CH50 was $25 \mathrm{U} / \mathrm{ml}$. Haptoglobin was $11.0 \mathrm{mg} / \mathrm{dl}$. Plasma ADAMTS13 activity was normal and ADAMTS13 inhibitor was not detected. Anti-cardiolipin antibody was negative, including anti-beta2 glycoprotein antibody and lupus anticoagulant.

After transfer to our hospital, renal biopsy was done 11 month after immunosuppression), and she was treated with prednisolone $(50 \mathrm{mg} /$ day) and cyclosporin A ( $250 \mathrm{mg} /$ day). In addition, plasma exchange was performed using FFP $(3,000 \mathrm{ml} \times 3$ days for 20 cycles $)$. After 1 month, her proteinuria, pancytopenia, and neurologic symptoms all subsided (table 1).

\section{Renal Histology}

Fixation and Processing of Biopsy Specimens

All renal tissue specimens from the 2 patients were examined by at least two pathologists using light microscopy (LM), direct immunofluorescence, and electron microscopy (EM). Specimens for LM were fixed in $6 \%$ formalin, embedded in paraffin, and cut into 


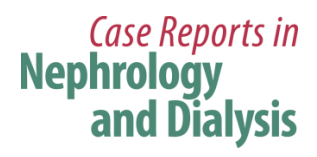

Case Rep Nephrol Dial 2015;5:192-199

DOI: 10.1159/000441107

C 2015 S. Karger AG, Basel

www.karger.com/cnd

Sekine et al.: Two Types of Renovascular Lesions in Lupus Nephritis with Clinical Thrombotic Thrombocytopenic Purpura

1-2- $\mu$ m thick sections. Then, staining was performed with hematoxylin and eosin (HE), periodic acid Schiff (PAS), Weigert's elastica-van Gieson, Masson's trichrome, or periodic acid methenamine silver (PAM) stain. Specimens for direct immunofluorescence were snapfrozen in a mixture of dry ice and acetone, and cut into 3-4- $\mu \mathrm{m}$ sections on a Damon/IEC cryostat at $-20^{\circ} \mathrm{C}$. After being fixed in acetone, the sections were incubated for $30 \mathrm{~min}$ in a moist chamber at $37^{\circ} \mathrm{C}$ with fluorescein isothiocyanate-conjugated (FITC) rabbit antiserum for human IgG, IgA, IgM, C1q, C3, and IgG subclasses (G1, G2, G3, and G4) (Behringwerke, Marburg, Germany, and Fuji Zoki, Japan). The slides were examined under an Olympus fluorescence microscope (Olympus Japan) equipped with an optimal excitation and barrier filter for FITC. For EM, renal biopsy cores were preserved in 3\% phosphate-buffered glutaraldehyde, diced into $1-\mathrm{mm}$ cubes, rinsed in distilled water, transferred to $1 \%$ aqueous osmium tetraoxide, and embedded in TAAB Emix resin. Sections were cut at a thickness of $0.5 \mu \mathrm{m}$, mounted on glass slides, and stained with $1 \%$ aqueous toluidine blue in $1 \%$ sodium tetraborate for $15 \mathrm{~s}$ on a hot plate at $150^{\circ} \mathrm{C}$. After cooling, LM was done to locate assessable glomeruli. Then, ultrathin sections were cut on a Leica Ultracut $\mathrm{E}$ ultramicrotome with a diamond knife, and were coated with gold particles having a diameter of approximately $95 \mathrm{~nm}$. Sections were stained by immersion for $7 \mathrm{~min}$ in $50 \%$ alcohol-saturated uranyl water and $3 \mathrm{~min}$ in Reynolds lead citrate, followed by three washes in distilled water. Then, the sections were examined under a Phillips 400 transmission EM.

\section{Findings in Case 1}

LM examination of renal specimens obtained at autopsy ( $3 \mathrm{~h}$ after the patient's death, and 2 months after immunosuppression) showed collapse of almost all glomeruli. Edematous widening of the subendothelial space was prominent in the glomerular capillary walls. Severe narrowing or occlusion by intraluminal thrombi affected almost all renal arteries from the pre-glomerular arterioles to the interlobular arteries (fig. 1a). Thrombi were positive for staining by PTAH, indicating fibrin deposition (fig. 1b). There was positive staining for IgG (including IgG1 and IgG3) (fig. 1c), IgA, and C3 (fig. 1d) along the walls of the small arteries, but intraluminal material was negative for IgG and C3. Although spike formation and double contours of the glomerular capillary walls were obscure, immunofluorescence revealed diffuse granular staining of the glomerular capillary walls for IgG (fig. 1c) (including IgG1 and IgG3), IgA, IgM, and C3. EM examination showed subepithelial electron-dense deposits. From these findings, membranous LN (class V) was diagnosed according to the 2003 ISN/RPS WHO classification, renal histological examination using autopsy was performed 2 months after immunosuppression. According to D'Agati's classification of the vascular lesions of LN, this renal histology was consistent with TMA, but positive staining of the walls of the small arteries for IgG and IgA is not included in this category by D'Agati.

\section{Findings in Case 2}

LM examination of a renal biopsy (that was performed 1 month after immunosuppression) specimen containing 47 glomeruli revealed no global sclerosis. Focal endocapillary glomerular lesions due to an increase of mesangial cells and endothelial cells with infiltrating monocytes and neutrophils, as well as narrowing of the glomerular capillaries, were seen in $<50 \%$ of all glomeruli, while fibrous adhesions between Bowman's capsule and the capillary walls were noted sometimes. Immunofluorescence revealed a diffuse granular pattern 


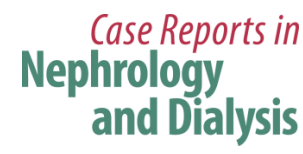

\begin{tabular}{l|l}
\hline Case Rep Nephrol Dial 2015;5:192-199 \\
\hline DOI: 10.1159/000441107 & $\begin{array}{l}\text { C 2015 S. Karger AG, Basel } \\
\text { www.karger.com/cnd }\end{array}$ \\
\hline
\end{tabular}

Sekine et al:: Two Types of Renovascular Lesions in Lupus Nephritis with Clinical Thrombotic Thrombocytopenic Purpura

of staining for IgG (especially IgG1 and IgG3), IgA, IgM, C3, and C1q in the mesangial regions as well as the glomerular capillary walls. EM examination displayed subendothelial and mesangial deposits, as well as a few subepithelial electron-dense deposits. LN (class III A/C) was diagnosed according to the 2003 ISN/RPS WHO classification, though renal biopsy was performed just before the second treatment. Severe narrowing or occlusion by intraluminal thrombi only affected some of the pre-glomerular arterioles (fig. 2a). Thrombi were negative for PTAH (fig. 2b). In this patient, there was positive staining of the walls of the small arteries and the intraluminal material for IgG (including IgG1 and IgG3) (fig. 2c), IgA, and C1q (fig. 2d). Noninflammatory necrotizing vasculopathy (so-called lupus vasculopathy) was diagnosed according to D'Agati's classification, but clinically this patient had TTP.

\section{Discussion}

D'Agati and Stokes [5] reclassified vascular lesions of LN, that Appel proposed [4], into five categories in 'Heptinstall's Pathology of the Kidney', which were (1) arteriosclerosis and arteriolosclerosis, (2) uncomplicated vascular immune deposits, (3) noninflammatory necrotizing vasculopathy (so-called lupus vasculopathy), (4) TMA, and (5) necrotizing vasculitis (PAN type). Categories 3 and 4 are summarized as follows. Category 3: the affected vessels are occluded by abundant deposits of eosinophilic material. Immunofluorescence shows positive staining for immunoglobulins (IgG, IgM, and IgA) and complement components (C3 and C1q). Rapid progression to renal failure with hypertension is seen. Clinical TTP is not included into this category. Category 4: LM reveals that the affected vessels are occluded by intraluminal fibrin thrombi. IgG is usually not found in these lesions. This type may occur in association with clinical HUS/TTP.

We encountered 2 patients with LN who met the clinical criteria for TTP and who had histological TMA of the small renal arteries. According to the classification of both D'Agati and Appel, our 2 cases share both histological features of category 3 and 4, but could not be classified into either category. Their small renal arteries showed positive staining for immunoglobulins and complement. Immunosuppressive therapy combined with plasmapheresis was performed for both patients. Case 1 progressed to end-stage renal failure requiring dialysis and this patient died, while the disease was controlled in case 2 . In refractory case 1 , there was mural staining of small renal arteries for IgG and C3, while intraluminal material was negative for immunoglobulins, although it was positive for PTAH (indicating fibrin deposition). In responsive case 2, there was mural staining of the small arteries for IgG, C1q, and C3, as well positive staining of intraluminal material for these immunoglobulins, while the intraluminal material was negative for PTAH. These findings suggest that when intraluminal thrombosis is closely associated with immune complexes, LN will respond to immunosuppressive therapy, while a response will be unlikely when intraluminal thrombosis is related to fibrin formation and not associated with immune complexes. Accordingly, among LN patients with clinical features of TTP, we report another two types of renovascular lesions with immune deposits, in addition to typical TMA with no immune deposits seen in nonlupus patients (D'Agati's category 4).

There were time differences between renal specimens from case 1 and 2 . In case 1 , the renal specimen was obtained at autopsy ( $3 \mathrm{~h}$ after her death, and 2 months after immunosuppression). In case 2, the renal specimen was obtained by a renal biopsy 1 month after immunosuppression. This limitation may contribute to the difference between the two renal histologies. 
Sekine et al.: Two Types of Renovascular Lesions in Lupus Nephritis with Clinical Thrombotic Thrombocytopenic Purpura

\section{Acknowledgment}

This study was funded by the Okinaka Memorial Institute for Medical Research.

\section{Disclosure Statement}

The authors have no conflicts of interest to disclose.

\section{Statement of Ethics}

The present report adhered to the Declaration of Helsinki, and the patients have given their consent for the case report to be published.

\section{References}

1 Alpers CE, Fogo AB: Kidney and its collecting system; in Kumar V, Abbas AK, Aster JC (eds): Robbins Basic Pathology, ed 9. Canada, Elsevier, 2013, pp 538-542.

-2 Lansigan F, Isufi I, Tagoe CE: Microangiopathic haemolytic anaemia resembling thrombotic thrombocytopenic purpura in systemic lupus erythematosus: the role of ADAMTS13. Rheumatology (Oxford) 2011;50:824-829.

-3 Matsuyama T, Kuwana M, Matsumoto M, Isonishi A, Inokuma S, Fujimura Y: Heterogeneous pathogenic processes of thrombotic microangiopathies in patients with connective tissue diseases. Thromb Haemost 2009;102:371-378.

-4 Appel GB, Pirani CL, D’Agati V: Renal vascular complications of systemic lupus erythematosus. J Am Soc Nephrol 1994;4:1499-1515.

5 D'Agati VD, Stokes MB: Renal disease in systemic lupus erythematosus; in Jennette JC, Olson JL, Schwartz MM, Silva FG: Heptinstall's Pathology of the Kidney, ed 7. Philadelphia, Wolters Kluwer, 2015, pp 571-577.

Table 1. Clinical information

\begin{tabular}{|c|c|c|c|c|c|c|}
\hline & \multirow{2}{*}{$\begin{array}{l}\text { Case } 1 \\
\text { before }\end{array}$} & \multirow[b]{2}{*}{ after 1 month } & \multirow[b]{2}{*}{ after 2 months } & \multicolumn{3}{|l|}{ Case 2} \\
\hline & & & & before & after 1 month & after 2 months \\
\hline $\mathrm{dsDNA}, \mathrm{IU} / \mathrm{ml}$ & 119 & 40 & 5 & 128 & 2.8 & $<1.0$ \\
\hline CH50, U/ml & 2 & 30 & 38 & 13 & 25 & 35 \\
\hline Cre, mg/dl & 1.4 & 12 (in hemodialysis) & 8 (in hemodialysis) & 1.4 & 0.8 & 0.8 \\
\hline Hemoglobin, g/dl & 5.2 & 4.8 & 4.6 & 6.2 & 7.9 & 11 \\
\hline Platelets, / $\mu \mathrm{l}$ & 54,000 & 31,000 & 18,000 & 48,000 & 65,000 & 226,000 \\
\hline $\begin{array}{l}\text { Haptoglobin, mg/dl } \\
\text { DC }\end{array}$ & $\begin{array}{l}12.1 \\
\text { coma }\end{array}$ & $\begin{array}{l}<10 \\
\text { deep coma }\end{array}$ & $\begin{array}{l}<10 \\
\text { deep coma (to death) }\end{array}$ & $\begin{array}{l}6 \\
\text { coma }\end{array}$ & $\begin{array}{l}11 \\
\text { normal }\end{array}$ & $\begin{array}{l}122 \\
\text { normal }\end{array}$ \\
\hline
\end{tabular}

DC = Disturbance of consciousness. 


\section{Case Reports in \\ Nephrology and Dialysis}

\begin{tabular}{l|l}
\hline \multicolumn{2}{l}{ Case Rep Nephrol Dial 2015;5:192-199 } \\
\hline DOI: 10.1159/000441107 & $\begin{array}{l}\text { @ 2015 S. Karger AG, Basel } \\
\text { www.karger.com/cnd }\end{array}$ \\
\hline
\end{tabular}

Sekine et al.: Two Types of Renovascular Lesions in Lupus Nephritis with Clinical Thrombotic Thrombocytopenic Purpura
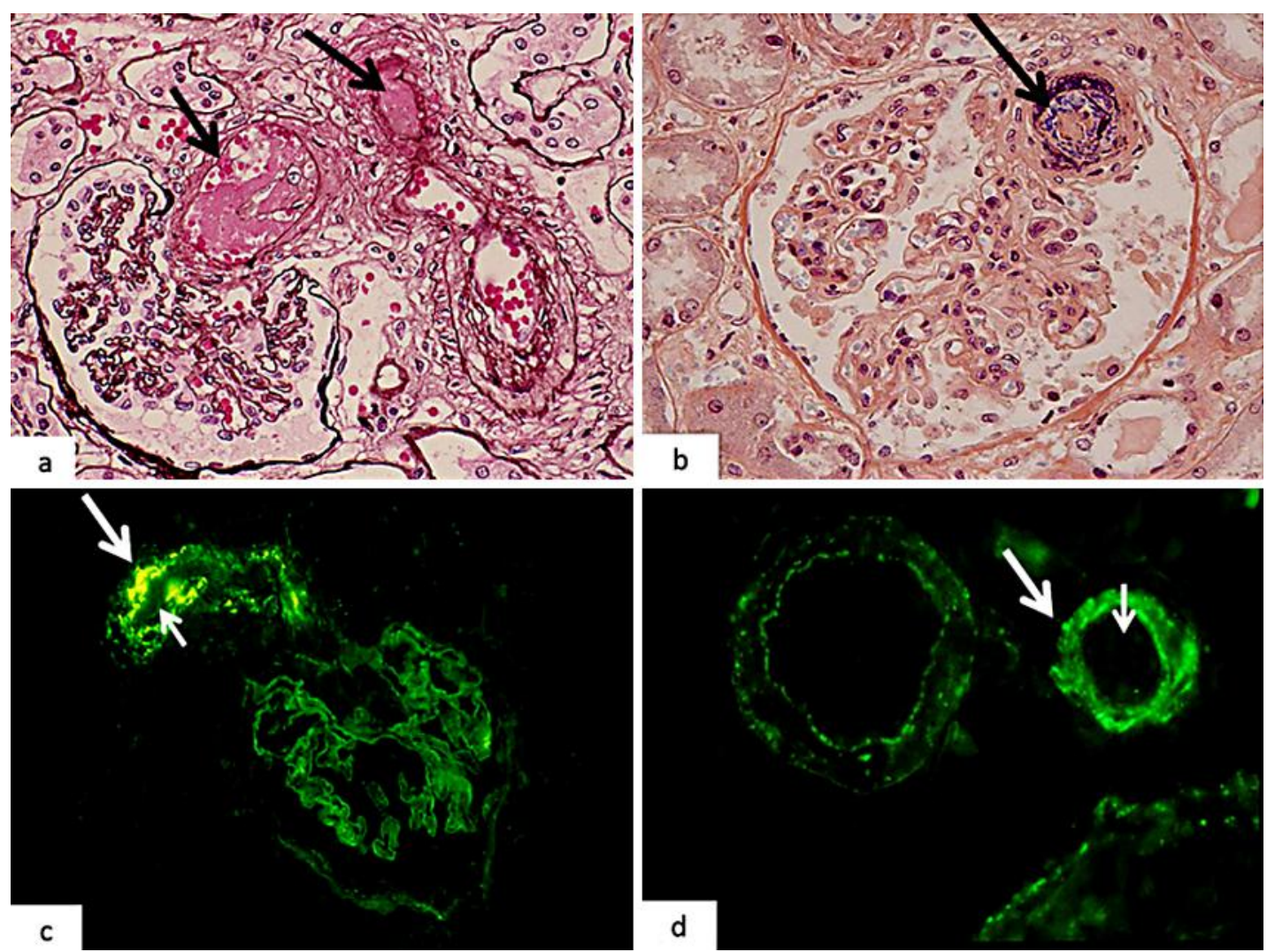

Fig. 1. a LM reveals that severe narrowing or occlusion by intraluminal thrombi (arrows) affects almost all pre-glomerular arterioles and interlobular arteries. PAM stain $(\times 400)$. b Thrombi (arrow) show positive PTAH staining, which indicates fibrin deposition $(\times 400)$. c Immunofluorescence microscopy shows positive staining for IgG along the walls of the small arteries (arrow), while intraluminal material is negative for IgG (small arrow). $\mathbf{d}$ Staining for C3 is positive along the walls of the small arteries (arrow), while intraluminal material is negative for C3 (small arrow). 


\section{Case Reports in \\ Nephrology \\ and Dialysis}

\begin{tabular}{l|l}
\hline \multicolumn{2}{l}{ Case Rep Nephrol Dial 2015;5:192-199 } \\
\hline DOI: $10.1159 / 000441107$ & $\begin{array}{l}\text { C } 2015 \text { S. Karger AG, Basel } \\
\text { www.karger.com/cnd }\end{array}$ \\
\hline
\end{tabular}

Sekine et al.: Two Types of Renovascular Lesions in Lupus Nephritis with Clinical Thrombotic Thrombocytopenic Purpura
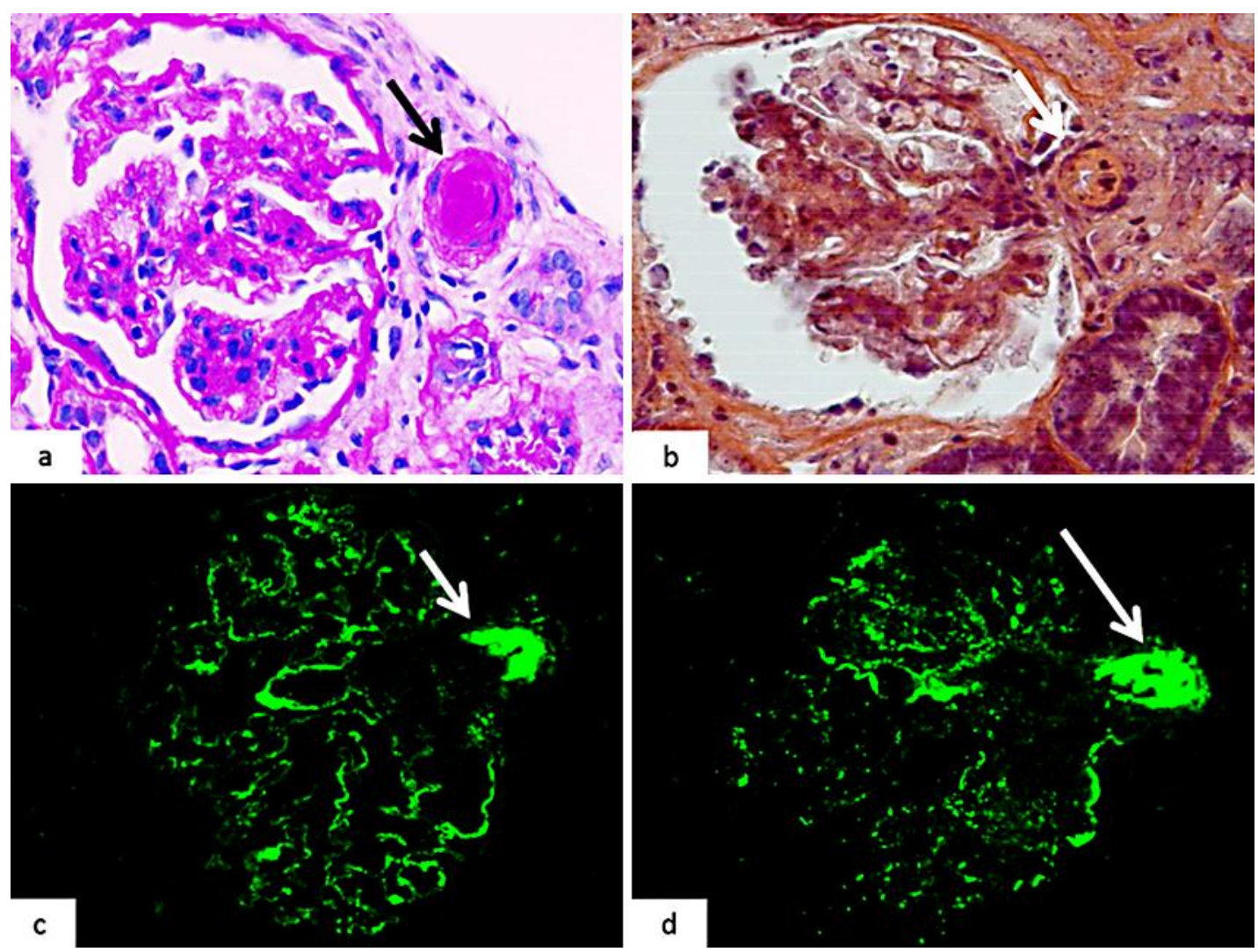

Fig. 2. a LM reveals class III (A/C) LN according to the 2003 ISN/RPS WHO classification, but severe narrowing or occlusion by intraluminal thrombi (arrow) only affects some pre-glomerular arterioles. PAS stain $(\times 400)$. b Thrombi are negative for PTAH stain $(\times 400)$ (arrow). c Immunofluorescence microscopy shows IgG staining of both the walls of the small arteries and the intraluminal material. $\mathbf{d}$ There is positive C1q staining of the walls of the small arteries as well as intraluminal material. 